\title{
XVII. On the alleged production of heat in mines by the condensation of the air which ventilates them; and on the fallacy of other objections to the opinion that a high temperature exists in the interior of the globe
}

\section{Robert W. Fox}

To cite this article: Robert W. Fox (1831) XVII. On the alleged production of heat in mines by the condensation of the air which ventilates them; and on the fallacy of other objections to the opinion that a high temperature exists in the interior of the globe, Philosophical Magazine Series 2, 9:50, 94-98, DOI: 10.1080/14786443108647549

To link to this article: http://dx.doi.org/10.1080/14786443108647549

册 Published online: 01 Jun 2009.

Submit your article to this journal ๔

Џ Article views: 2 


\section{[ 94 ]}

XVII. On the alleged Production of Heat in Mines by the Condensation of the Air which ventilates them; and on the Fallacy of other Objections to the Opinion that a ligh Temperature exists in the Interior of the Globe. By Roв ERTW. Fox.

\section{To the Editors of the Philosophical Magazine and Annals.}

Gentlemen,

A PAPER has recently appeared in the Edinburgh Re-

view* " On the Progress of Geological Science," in which arguments are adduced against the existence of an elevated temperature in the interior of the earth.

These arguments are founded on the cold which prevails about the poles, notwithstanding they are twelve miles nearer the centre than the surface of the earth is at the equator; and on the comparatively low temperature of the water in abandonded mines, as well as at the bottom of the sea, as far as this has been ascertained.

It is at the same time admitted that the heat is found to increase in mines in proportion as they are deepened, and that its degree depends on their depth under the surface, rather than with respect to the level of the sea. That it is not produced by the miners, and the candles and gunpowder they use, is fully acknowledged, as the influence of those causes must be perfectly insignificant on the large quantity of water pumped out of deep mines.

But the reviewers attribute the elevation of temperature observed in mines to the condensation of the currents of air which ventilate them. "Now," they say, " as this air passes from the surface to the bottom of the minet, it becomes more and more compressed. Its temperature in consequence must be continually increasing, and of course it must be always giving out heat to the walls of the mine and to the water with which it comes in contact. The heat given out at the bottom will be greatest, because there the compression is greatest. The greater the quantity of air thus condensed, and the more rapid the current, the greater will be the quantity of heat evolved. This, we are persuaded, is the true cause of the elevation of temperature as a mine increases in depth."

These opinions, proceeding from such authority, induce me, from the part I have taken in this question, and the opportunities I possess, from my local situation, for getting information relative to the Cornish mines, to offer a few remarks

* Edinburgh Review, No. 103, p. 49-52.

$\uparrow$ Dolcoath is the mine referred to, and $84^{\circ}$ the temperature of the water at the bottom, the mine being 238 fathoms deep. 
Mr. R. W. Fox on the Increase of Heat in Mines.

for the purpose of showing that neither the hypothesis, nor the objections derived from the temperature of abandoned mines, are tenable.

I do not apprehend that a degree of pressure equal to what takes place in our deepest mines would raise the temperature of air many degrees, probably not more than five or six at the utmost, supposing none of the heat to escape to surrounding bodies; but the water flows into some of our mines in considerable streams at the temperature of from $80^{\circ}$ to $90^{\circ}$, which is about $30^{\circ}$ to $40^{\circ}$ above that of the climate : and nearly two millions of gallons are daily pumped from the bottom of Poldice mine, which is 176 fathoms deep, at $99^{\circ}$ to $100^{\circ}$. This being warmer than the human body, of course puts that source of heat out of the question; and it often happens that streams of water, the moment they gush into mines, are equal and sometimes superior in temperature to the air immediately in contact with them.

Neither do the seasons seem to produce any sensible effect in deep mines, which they doubtless would do if the heat were in almost any degree attributable to the compression of the air.

Our mines are for the most part ventilated by shafts opening into the levels or galleries from the surface or from a higher level. These shafts are commonly numerous in extensive mines, and the air circulates freely and often copiously through them, ascending in some shafts, and descending in others. In all cases, I believe that the upward currents are at a higher temperature than the downward ones; so much so, indeed, that in winter the moisture is often frozen in the latter to a considerable depth, and not at all in the former. The temperature of these currents has recently been ascertained in some mines.

In Dolcoath the air ascended in one shaft at $60^{\circ}$, and descended in another at $51^{\circ}$ :- the thermometer was placed six feet down in these shafts.

In Poldice a current came up at $61^{\circ}$, and another went down at $48^{\circ}$, both having been observed at thirty feet below the mouths of the shafts.

In Tingtang mine, which is $\mathbf{1 7 8}$ fathoms deep, the thermometer was let down fifteen feet in two shafts, and indicated a temperature of $59^{\circ}$ in the ascending, and $42^{\circ}$ in the descending current.

The inferior specific gravity of the heated air is, in fact, the cause of its ascent, and consequently of the descent of fresh supplies from the atmosphere at a lower temperature; so that 
it is clear that the air which circulates in mines tends to diminish, and not to augment their temperature. The air supplied by mechanical means is comparatively trifling; this mode of ventilation being resorted to only, when, from a deficiency of shafts, the circulation is very imperfect; and as it must ul= timately form a part of the warm ascending currents, it is unnecessary to consider its effect on temperature as a distinct question.

True it is, that the ratio of increase is by no means uniform in the mines; nor ought it to be expected to be so, as there are many disturbing causes which must affect the temperature very differently in different places. Of these, the copious filtration of water into the deepest excavations of mines, is, I conceive, the most influential, subject as it is in a peculiar degree to be modified by local circumstances both in its quantity and direction. It cannot however be doubted that it must chiefly come from more elevated ground; and therefore I think it may be inferred, that the temperature of mines is not equal to that of the earth at the same level, either in degree or in uniformity.

The temperature of water in the shafts of abandoned mines has been repeatedly referred to in opposition to the opinion that a native heat exists in the earth itself. On this subject I have made some observations in a paper published, in 1827, in the third volume of the Cornwall Geological Society's Transactions, which I may perhaps be allowed to quote.

"My impression is, that the experiments which have been made in these collections of water tend to support the opinions". (in favour of a subterranean heat), " the differences of temperature being considerable in different stopped mines; and even in different shafts of the same mine a variation of temperature has been observed.

"Some very shallow mines, it seems, have been found full of water to the adit level at the temperature of $51^{\circ}$; others; at from $52^{\circ}$ to $56^{\circ}$, and even $57^{\circ}$, as was the case at Gunnis Lake copper mine, the depth of which was 125 fathoms, and the adit 35 fathoms, from the surface; so that, taking the mean temperature of the climate at as high as $51^{\circ}$, (which, from some experiments to be mentioned*, I now think is rather above the mark, as it respects our principal mining di-

\footnotetext{
* A series of observations, continued throughout the year, made on the temperature of the ground, and three feet under the surface, gave for Dolcoath $49^{\circ} .94$; and Huel Gorland, which is more elevated, being about 350 feet above the sea-level, $48^{\circ} \cdot 99$.
} 
stricts at least,) it gives an excess of five or six degrees for the whole of the water in some shafts, which is equal to ten or twelve degrees for the extreme, even supposing equal quantities of water to flow into the shafts from the higher and lower galleries : this, however, I imagine to be by no means the case, but that by far the largest portion of what is emptied into the adits from the overflow of the waters in shafts *, must be derived from the upper levels and workings of mines. The levels are usually driven on the veins at intervals of ten fathoms under the adits; the superior ones being more extended in length than the inferior; so that they are likely to intercept most of the waters coming from the ground above; and the water following that course which opposes the least resistance may be supposed to pass principally through the uppermost levels into the shafts, and to sink therein, if its relative temperature be low. Thus it may be presumed that the comparatively stationary water in the deeper levels, has but little influence on that in the shafts; for it is well known that this fluid conducts heat in a lateral direction very slowly.

"The effects above mentioned are doubtless variously modified in different places by the nature and thickness of the strata and the more or less pervious state of the veins: besides, the workings communicating with the shafts are in some mines much more open and excavated than in others. And considering all these circumstances, we might, I think, anticipate that the results of experiments on the temperature of water in stopped mines must be discordant and inconclusive as to the actual heat of the earth itself, however strongly they may colroborate the truth of its existence."

I might have added, that there are usually several shafts in mines not carried down through the adit, which must receive large supplies of rain-water from the surface; and this water having, it may be presumed, a mean temperature less than that of the climate, of course tends to diminish the temperature of the water in abandoned mines.

The experiments made to ascertain the temperature of the ocean at great depths are, I think, quite inconclusive with respect to the subject under consideration. The bed of the sea is doubtless composed of very imperfect conductors of heat; but if it were all of solid rock, it would surely be incapable of transmitting heat to the water so fast as the latter would convey it away, not only from its natural tendency, when heated, to ascend in colder portions of that fluid, but also from the

- The quantity of the waters so discharged from the shafts, is generally considerable.

N. S. Vol. 9. No. 50. Feb. 1831. 
incessant agitation of the ocean produced by currents and tides, \&c. For these reasons, it appears to me that a low temperature at the bottom of the sea is not at all inconsistent with a high degree of terrestrial heat.

The temperature about the poles of the earth must also be governed by the relative impressions of the heat and cold to which they may be exposed; and if frost and snow are found on Hecla and other volcanic mountains and districts, owing to the very slowly and imperfectly conducting medium of the rocks and the ground, surely the effects produced by the cold in the polar regions cannot be deemed incompatible with an elevated temperature under the surface. The zones of equal temperatures at accessible depths in the earth having been found to conform, in some degree, to the irregularities of its surface,- - this fact affords another instance that whilst the internal parts of mountains and hills may be sustained at a high temperature, their sides and even the valleys which separate them may be quite cold. 'This arrangement of the zones of heat must, I conceive, cause the water or moisture in the interior of mountains and hills to give out vapour more or less copiously, according to circumstances; and this ascending towards their summits and sides, gradually condenses into drops in proportion as the temperature of the ground diminishes. The drops accumulating into small streams, ultimately appear, in part at least, at the surface, and form a more or less considerable proportion of springs or fountains.

If the terrestrial temperature could be determined with certainty at any given depths within our reach, I much question whether it ought to be considered as furnishing us with proper data for calculating the ratio of increase to a far greater depth, because it appears to me to be highly probable that in the former case the heat may be due to the ascending portions of warm water, more than to the conducting power of the rocks; and this idea derives confirmation from the fact, that those rocks which most readily transmit heat (compact granite for example) are usually found at a lower temperature in mines than clay-slate and other rocks which are the most pervious to moisture and the worst conductors of heat.

It must however be acknowledged that whether the terrestrial heat increases more or less rapidly towards the centre, the frequent occurrence of volcanos and hot springs, in districts far separated from each other, tends strongly to confirm the opinion that a very high temperature exists in the interior of the globe.

Falmouth, Jan. 13, 1831.

Robert W. Fox.

XVIII. On 